\title{
Melatonin and alpha lipoic acid attenuate methotrexate/ cisplatin-induced kidney toxicity in albino rats
}

\author{
Elias Adikwu $^{{ }^{*} \mathbb{\oplus}}$, Nelson Clement Ebinyo ${ }^{1}$, Bonsome Bokolo $^{2}$ \\ ${ }^{1}$ Department of Pharmacology and Toxicology, Faculty of Pharmacy, Niger Delta University, Bayelsa State, Nigeria \\ ${ }^{2}$ Department of Pharmacology, Faculty of Basic Medical Sciences, College of Health Sciences, Niger Delta University, Bayelsa State, Nigeria
}

\section{A R T I C L E I N F O}

Article Type:

Original

\section{Article History:}

Received: 9 April 2019

Accepted: 14 August 2019

Published online: 19 October 2019

Keywords:

Anticancer

Antioxidants

Kidney

Toxicity

Protection

Melatonin

Alpha lipoic acid

Methotrexate

Cisplatin

\begin{abstract}
A B S T R A C T
Introduction: Most anticancer therapies are seldom effective by single anticancer drug due to biologic heterogeneity and multiple genetic alterations stimulating the use of anticancer drug combinations. Methotrexate/cisplatin (MTX/CPT) has shown beneficial effects in the treatment of metastatic and malignant tumors, but its use may perturb kidney function.

Objectives: The present study assessed the protective effects of melatonin (MT) and alpha-lipoic acid (ALA) against kidney toxicity induced by MTX/CPT in albino rats.

Materials and Methods: Forty-eight adult male albino rats were randomized into groups and pretreated with MT (10 mg/kg), ALA (10 mg/kg) and MT+ALA daily for five days before treatment with $20 \mathrm{mg} / \mathrm{kg}$ of MTX and $5 \mathrm{mg} / \mathrm{kg}$ of CPT intraperitoneally on the fifth day. After overnight fast, rats were sacrificed, serum samples were centrifuged from blood samples and assessed for renal function parameters and electrolytes. Kidneys were assessed for oxidative stress (OS) markers and pathology.

Results: Significant $(P<0.001)$ increases in serum creatinine, urea, and uric acid levels with significant $(P<0.001)$ decreases in total protein, albumin, potassium, sodium, chloride, and bicarbonate levels were obtained in MTX/CPT-intoxicated rats when compared to control. Furthermore, kidney malondialdehyde levels were significantly $(P<0.001)$ increased whereas catalase, superoxide dismutase, glutathione and glutathione peroxidase levels were significantly $(P<0.001)$ decreased in MTX/CPT-intoxicated rats when compared to control. Pathologic changes marked by atrophic glomeruli were detected in the kidneys of MTX/CPT-treated rats. However, nephrotoxicity observed in MTX/CPT-treated rats was significantly reversed in MT $(P<0.01)$, ALA $(P<0.05)$ and MT+ALA $(P<0.001)$ pretreated rats when compared to MTX/CPT -treated rats. Conclusion: MT and ALA supplementations attenuate nephrotoxicity caused by MTX/CPT.
\end{abstract}

\section{Implication for health policy/practice/research/medical education:}

This study discovered that supplementations with melatonin and alpha lipoic acid attenuate kidney injury caused by methotrexate/ cisplatin.

Please cite this paper as: Adikwu E, Ebinyo NC, Bokolo B. Melatonin and alpha lipoic acid attenuate methotrexate/cisplatininduced kidney toxicity in albino rats. J Nephropharmacol. 2020;9(2):e17. DOI: 10.34172/npj.2020.17.

\section{Introduction}

Most cancers have been associated with genetic alterations thereby becoming resistant to monotherapy which is a serious clinical challenge. One of the primary means of overcoming cancer resistance to monotherapy is the therapeutic use of anticancer drug combinations (anticancer drug cocktail) (1). Anticancer drug cocktail enhances efficacy because it targets key pathways in an additive or synergistic manner. This therapeutic approach reduces drug resistance, provides therapeutic anti-cancer benefits such as reducing cancer metastasis, growth and killing rapidly active and dividing cancer cells. However, the use of anticancer cocktail can be associated with some disadvantages which include synergistic or additive toxicities (2).

Methotrexate and cisplatin (MTX/CPT) combination which has shown comparative advantage over monotherapy is active against cancer with multiple genetic alterations. It has shown efficacy in metastatic penile squamous cell carcinoma (3). It is superior to single-agent with respect to response rate, duration of remission, and overall survival in patients with advanced and malignant urothelial carcinoma (4). Additionally, MTX/CPT is an effective regimen for patients with metastatic transitional 
cell carcinoma of the bladder and buccal mucosa $(5,6)$. However, one of the primary concerns with the use of MTX/CPT is the possible development of toxicities including nephrotoxicity. MTX can cause nephrotoxicity in $2 \%-12 \%$ of cancer patients whereas CPT can cause nephrotoxicity in $20 \%-30 \%$ of cancer patients with $28 \%$ $36 \%$ caused by its single dose $(7,8)$. Hence concurrent administration can predispose the kidney to severe toxicity. The nephrotoxic effect of MTX/CPT can occur through multiple mechanisms which include direct toxicity, oxidative stress (OS), induction of cell apoptosis and inflammation through the production of proinflammatory mediators such as tumor necrosis factor alpha (TNFa) and interleukin 6 (IL-6) $(8,9)$.

Melatonin (MT) is an indole amine that is secreted by the pinealgland (10). It is also present in bacteria, fungiand plants (11). MT has drawn lots of attentions due to its physiologic and pharmacologic activities. It has shown in-vivo and in-vitro antioxidant activity including its metabolites, N1-acetyl-N2-formyl-5-methoxykynuramine, and N1acetyl-5-methoxykynuramine. The antioxidant effect of MT has been attributed to its ability to terminate or inhibit the detrimental activities of free radicals which include peroxynitrite anions, oxygen radicals, hydroxyl radicals, and alkoxy radicals (12). Also, it can increase antioxidant gene expression thereby facilitating antioxidant production and increase activities (13). Its inhibitory effect on free radicals has protected cellular DNA, lipids and proteins from OS-induced damage (14). MT has antiinflammatory activity and has been shown to reduce the translocation of NF- $\kappa B$, thereby inhibiting the synthesis of pro-inflammatory cytokines (15). Furthermore, MT can modulate a variety of neural, endocrine and immune functions and has shown potential benefits in autoimmune conditions, such as rheumatoid arthritis, asthma, organ transplantation and some pathologic conditions (16).

Alpha-lipoic acid (ALA) is a dithiol compound derived from octanoic acid which plays an essential role in mitochondrial dehydrogenase reactions. It acts as a cofactor in multi-enzyme complexes and is an essential substance in energy production via the citric acid cycle (17). It is a potent antioxidant that delivers antioxidant activity in fat- and water-soluble media in its oxidized (LA) and reduced dihydrolipoic acid (DHLA) form (17). DHLA is capable of exerting antioxidant effect by donating electrons to a pro-oxidant or an oxidized molecule (18). ALA can enhance the activities of mitochondrial enzymes, decrease levels of ROS and regenerates the activities of other antioxidants $(19,20)$. Furthermore, the free radical scavenging activity of ALA can inhibit OS, lipid peroxidation (LPO) and prevent cellular DNA, lipids, and proteins from damage $(21,22)$. Additionally, it has exhibited potential therapeutic effects on conditions which include hypertension, Alzheimer disease, obesity, cancer, glaucoma and diabetes (23). This study examined the protective effects of ALA and MT against kidney toxicity induced by MTX/CPT in albino rats.

\section{Materials and Methods}

Drugs/Chemicals

MT and ALA were supplied by Shijiazhuang AO Pharm Import and Export Co Ltd China. MTX and CPT were manufactured by Biochem Pharmaceutical industries limited India.

\section{Animals}

Adult male albino rats with average weight of $225 \mathrm{~g}$ used for this study were obtained from the animal house of the Department of Pharmacology and Toxicology, Niger Delta University, Nigeria. The rats were housed in cages (6 per cage) and allowed to acclimatize for one week in a well -ventilated room, maintained at a room temperature of $28 \pm 2^{\circ} \mathrm{C}$, under natural light/dark cycle. Rats were fed with standard rodent chew and given tap water ad libitum.

\section{Animal treatment}

Forty-eight adult male albino rats were grouped into four groups (A-D). Group A (control) contained six rats which were treated intraperitoneally (ip) with $0.2 \mathrm{~mL}$ of normal saline daily for 5 days. Group B contained 18 rats which were divided into three subgroups (BI-B3) and were treated ip with $10 \mathrm{mg} / \mathrm{kg}$ of MT (24), $10 \mathrm{mg} / \mathrm{kg}$ of ALA (24) and MT+ALA daily for 5 days respectively. Group $\mathrm{C}$ contained six rats which were treated with $20 \mathrm{mg} / \mathrm{kg}$ of MTX (25) and $5 \mathrm{mg} / \mathrm{kg}$ of CPT (26) on the fifth day. Group D contained 18 rats which were subdivided into three groups (D1-D3) of six rats each and were pretreated ip with $10 \mathrm{mg} / \mathrm{kg}$ of MT, $10 \mathrm{mg} / \mathrm{kg}$ of ALA and MT+ALA daily for 5 days before treatment with MTX and CPT ip on the fifth day. Rats were sacrificed after treatment under ether anesthesia, blood samples were collected and kidneys harvested through dissection.

\section{Biochemical analysis}

Blood samples were centrifuged at $2000 \mathrm{~g}$ for 15 minutes to separate serum samples from blood cells. Serum urea, creatinine, uric acid, total protein, and albumin levels were determined by routine colorimetric methods using commercial diagnostic test kits (Randox Laboratories Ltd., Crumlin, UK). Kidney samples taken were washed in saline in an ice bath and homogenized with ice-cold $150 \mathrm{mM} \mathrm{KC1}$ and evaluated for OS markers. Kidney malondialdehyde (MDA) was assayed as reported by Buege and Aust (27) whereas reduced glutathione (GSH) was evaluated as reported by Sedlak and Lindsay (28). Superoxide dismutase (SOD) was measured as reported by Misra and Fridovich (29) whereas catalase (CAT) was analysed using the method of Aebi (30). Glutathione peroxidase (GPX) was assayed according to Rotruck et al (31). 
Preparation of kidney tissues for histological examination Sections of the kidneys of rats were taken and gently rinsed with physiological saline solution $(0.9 \% \mathrm{NaCl})$. Kidney tissues were fixed in $75 \mathrm{~mL}$ of saturated aqueous picric acid, $25 \mathrm{~mL}$ of formaldehyde and glacial acetic acid for $24 \mathrm{hr}$. Kidney tissues were processed and embedded in paraffin wax. Sections of $5 \mu \mathrm{m}$ thickness were cut using microtome. The sections were stained with hematoxylin and counter stained with eosin, dissolved in 95\% alcohol. The stained sections were examined using a light microscope.

\section{Ethical issues}

The approval for this study was granted by the Research Ethics Committee of the Department of Pharmacology and Toxicology, Faculty of Pharmacy, Niger Delta University, Nigeria. Prior to the experiment, the protocols were confirmed to be in accordance with the guidelines of the Animal Ethics Committee of Niger Delta University, Nigeria

\section{Statistical analysis}

Data are represented as the mean \pm SEM. One-way analysis of variance (ANOVA) followed by Tukey's multiple comparison tests were used to assess statistical significance. A $P$ value less than $0.05 ; 0.01$ and 0.001 was considered significant.

\section{Results}

Effects on body and kidney weights and serum renal function markers

Normal $(P>0.05)$ body and kidney weights and serum creatinine, urea, uric acid, total protein and albumin levels were obtained in MT and ALA -treated rats when compared to control (Figures 1-5) (Table 1). Body and kidney weights were normal $(P>0.05)$ however, serum creatinine, urea and uric acid levels were significantly $(P<0.001)$ increased whereas total protein and albumin levels were significantly $(P<0.001)$ decreased in rats treated with MTX/CPT when compared to control (Figures 1-5) (Table 1). In contrast, serum creatinine, urea and uric acid levels were significantly decreased whereas total protein and albumin levels were significantly increased in MT $(P<0.01)$, ALA $(P<0.05)$ and MT+ALA $(P<0.001)$ pretreated rats when compare to MTX/CPTtreated rats (Figures 1-5).

\section{Effect on serum electrolytes}

Furthermore, normal $(P>0.05)$ levels of serum $\mathrm{K}^{+}, \mathrm{Na}^{+}$, $\mathrm{Cl}^{-}$and $\mathrm{HCO}_{3}^{-}$were obtained in rats treated with $\mathrm{MT}$ and ALA when compared to control. In contrast, serum $\mathrm{K}^{+}$, $\mathrm{Na}^{+}, \mathrm{Cl}^{-}$and $\mathrm{HCO}_{3}^{-}$levels were significantly $(P<0.001)$ decreased in rats treated with MTX/CPT when compared to control (Table 2). The decreases in serum $\mathrm{K}^{+}, \mathrm{Na}^{+}, \mathrm{Cl}^{-}$and $\mathrm{HCO}_{3}{ }^{-}$levels were significantly restored in $\mathrm{MT}(P<0.01)$

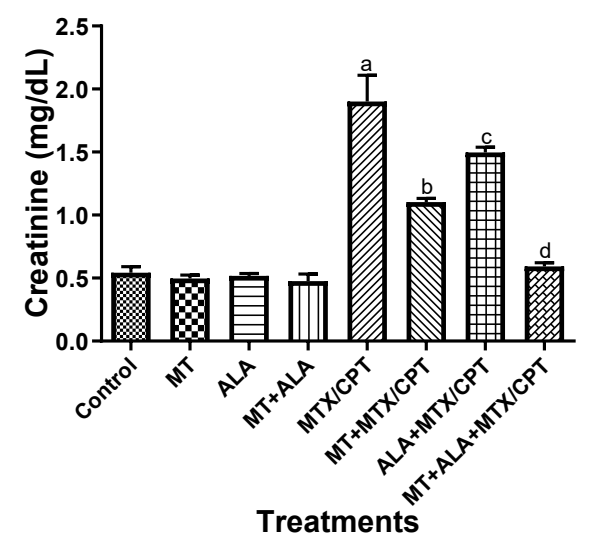

Figure 1. Effects of melatonin and alpha lipoic acid on serum creatinine of methotrexate/cisplatin -treated albino rats.

MTX/CPT; Methotrexate/Cisplatin, MT; Melatonin, ALA; Alpha lipoic acid, $\mathrm{n}=6$, Data are expressed as Mean \pm SEM. ${ }^{a}$ Significant $(P<0.001)$ difference when compared to control, ${ }^{b}$ Significant difference $(P<0.01)$ when compared to MTX/CPT, ${ }^{c}$ Significant difference $(P<0.05)$ when compared to MTX/CPT, ${ }^{d}$ Significant difference $(P<0.001)$ when compared to MTX/CPT.

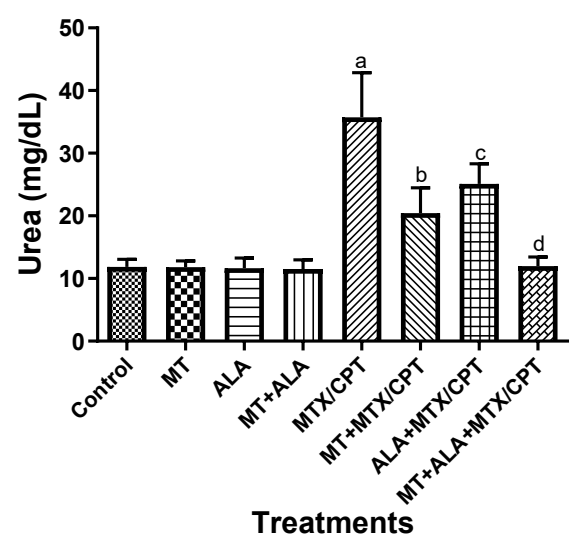

Figure 2. Effects of melatonin and alpha lipoic acid on serum urea of methotrexate/cisplatin-treated albino rats.

MTX/CPT; Methotrexate/Cisplatin, MT; Melatonin, ALA; Alpha lipoic acid, $\mathrm{n}=6$, Data are expressed as Mean \pm SEM. a Significant $(P<0.001)$ difference when compared to control, b Significant difference $(P<0.01)$ when compared to MTX/CPT, ${ }^{\circ}$ Significant difference $(P<0.05)$ when compared to MTX/CPT, d Significant difference $(P<0.001)$ when compared to MTX/CPT.

and ALA $(P<0.05)$ pretreated rats when compared to MTX/CPT-treated rats. However, the restored levels of $\mathrm{K}^{+}, \mathrm{Na}^{+}, \mathrm{Cl}^{-}$and $\mathrm{HCO}_{3}{ }^{-}$were significant at $P<0.001$ in rats pretreated with MT+ALA when compared to MTX/CPT -treated rats (Table 2).

Effects on kidney oxidative stress markers and histology The kidney levels of MDA, SOD, CAT, GSH and GPX were $(P>0.05)$ normal in rats treated with $\mathrm{MT}$ and ALA when compared to control. On the other hand, kidney SOD, CAT, GSH and GPX levels were decreased 


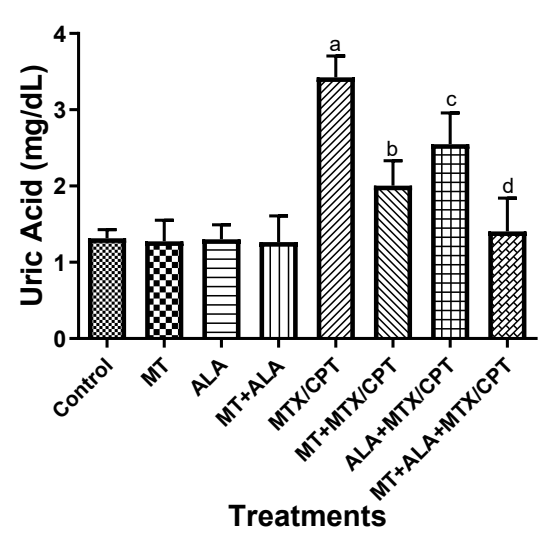

Figure 3. Effects of melatonin and alpha lipoic acid on serum uric acid of methotrexate/cisplatin-treated albino rats.

MTX/CPT; Methotrexate/Cisplatin, MT; Melatonin, ALA; Alpha lipoic acid, $\mathrm{n}=6$, Data are expressed as Mean \pm SEM. a Significant $(P<0.001)$ difference when compared to control, b Significant difference $(P<0.01)$ when compared to MTX/CPT, ${ }^{c}$ Significant difference $(P<0.05)$ when compared to MTX/CPT, d Significant difference $(P<0.001)$ when compared to MTX/CPT.

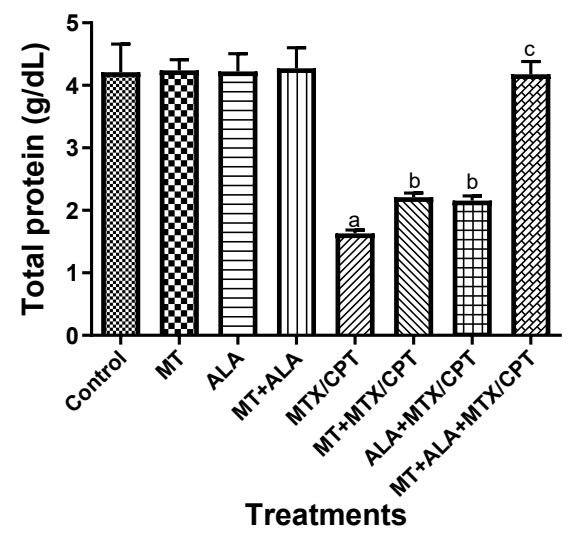

Figure 4. Effects of melatonin and alpha lipoic acid on serum total protein of methotrexate/cisplatin-treated albino rats.

MTX/CPT; Methotrexate/Cisplatin, MT; Melatonin, ALA; Alpha lipoic acid, $\mathrm{n}=6$, Data are expressed as Mean \pm SEM. a Significant $(P<0.001)$ difference when compared to control, b Significant difference $(P<0.01)$ when compared to MTX/CPT, ${ }^{c}$ Significant difference $(P<0.001)$ when compared to MTX/CPT.

significantly $(P<0.001)$ whereas MDA levels were increased significantly $(P<0.001)$ in rats treated with MTX/CPT when compared to control (Table 3). However, SOD, CAT, GSH and GPX levels were increased whereas MDA levels were decreased significantly in $\mathrm{MT}(P<0.01)$, ALA $(P<0.05)$ and MT+ALA $(P<0.001)$ pretreated rats when compared to MTX/CPT-treated rats (Table 3$)$. The kidney of control rat showed normal histology (Figure 6A) whereas the kidney of rat treated with MTX/CPT showed atrophic glomerulus (Figure 6B). On the other hand, the kidneys of rats pretreated with individual doses of MT and ALA showed normal glomeruli (Figure 6C and D). Moreover, the kidney of rat pre-treated with MT+ALA showed normal glomerulus (Figure 6E).

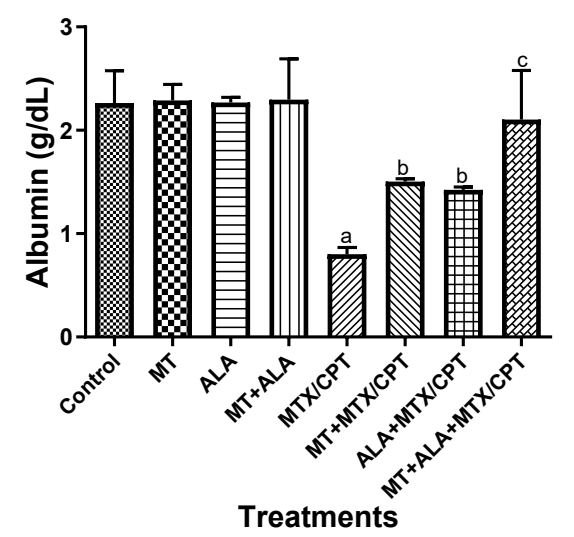

Figure 5. Effects of melatonin and alpha lipoic acid on serum albumin of methotrexate/cisplatin-treated albino rats.

MTX/CPT; Methotrexate/Cisplatin, MT; Melatonin, ALA; Alpha lipoic acid, $\mathrm{n}=6$, Data are expressed as Mean \pm SEM. a Significant $(P<0.001)$ difference when compared to control, ${ }^{b}$ Significant difference $(P<0.01)$ when compared to MTX/CPT, ${ }^{c}$ Significant difference $(P<0.001)$ when compared to MTX/CPT.

\section{Discussion}

Most cancers are associated with biologic heterogeneity and multiple genetic alterations limiting the efficacy of mono therapy, but this challenge has been relatively subdued by therapy with anticancer drug combinations (32). Clinically, MTX/CPT has shown curative effects against metastatic penile, urothelial, and buccal carcinoma and other forms of carcinoma, but an essential concern is the possible development of toxicities including nephrotoxicity. A number of mechanisms have been linked with anticancer agent-induced nephrotoxicity which include direct toxicity, OS, inflammation, cellular necrosis and apoptosis (33). MT and ALA are antioxidant and anti-inflammatory agents that can inhibit the activities of ROS and pro-inflammatory mediators. They have shown potential curative effects against some animal models of diseases such as diabetes, hypertension and hyperlipidemia $(34,35)$. The present study assessed whether MT and ALA can offer protection against a rat model of MTX/CPT-induced kidney toxicity. Biochemical markers play important roles in accurate diagnosis and target-oriented-therapy with the assurance of the desired clinical outcome. Serum creatinine, urea and uric acid are biochemical markers of renal function. Serum creatinine evaluation is used to monitor the progression of renal disease whereas urea is useful in differential diagnosis of acute renal failure and pre-renal condition. Additionally, the assessment of serum protein differentiates between glomerular and tubulointerstitial diseases and predicts the progress of renal disease (36). When the integrity of the kidney is compromised due to toxic insults, the concentrations of the aforementioned renal markers are usually altered (36). In this study, all evaluated kidney function markers were normal in MT and ALA-treated rats. However, kidney function was compromised in 
Table 1. Effects of melatonin and alpha lipoic acid on body and kidney weights of methotrexate/cisplatin-treated albino rats

\begin{tabular}{|c|c|c|c|c|c|c|c|c|}
\hline Parameters & Control & MT & ALA & $M T+A L A$ & MTX/CPT & $\begin{array}{c}\mathrm{MT}+\mathrm{MTX} / \\
\mathrm{CPT}\end{array}$ & $\begin{array}{c}A L A+M T X / \\
\text { CPT }\end{array}$ & $\begin{array}{c}\text { MTX+ ALA+ } \\
\text { MTX/CPT }\end{array}$ \\
\hline $\begin{array}{l}\text { Final body weight } \\
\text { (g) }\end{array}$ & $220.5 \pm 12.0$ & $223.9 \pm 11.1$ & $221.1 \pm 12.7$ & $230.9 \pm 13.5$ & $215.0 \pm 12.2$ & $219.6 \pm 10.7$ & $217.4 \pm 10.8$ & $235.6 \pm 12.5$ \\
\hline Kidney weight (g) & $0.64 \pm 0.05$ & $0.63 \pm 0.01$ & $0.64 \pm 0.05$ & $0.66 \pm 0.01$ & $0.68 \pm 0.08$ & $0.67 \pm 0.03$ & $0.65 \pm 0.08$ & $0.63 \pm 0.02$ \\
\hline $\begin{array}{l}\text { Relative kidney } \\
\text { weight (\%) }\end{array}$ & $0.29 \pm 0.06$ & $0.28 \pm 0.01$ & $0.30 \pm 0.06$ & $0.29 \pm 0.05$ & $0.32 \pm 0.03$ & $0.31 \pm 0.07$ & $0.30 \pm 0.04$ & $0.27 \pm 0.07$ \\
\hline
\end{tabular}

MTX/CPT; Methotrexate/Cisplatin, MT; Melatonin, ALA; Alpha lipoic acid, $n=6$, Data are expressed as mean \pm SEM.

Table 2. Effects of melatonin and alpha lipoic acid on serum electrolytes of methotrexate/cisplatin-treated rats

\begin{tabular}{|c|c|c|c|c|}
\hline Groups & $\mathrm{K}^{+}(\mathrm{mmo} / \mathrm{L})$ & $\mathrm{Cl}^{-}(\mathrm{mmo} / \mathrm{L})$ & $\mathrm{Na}^{+}(\mathrm{mmo} / \mathrm{L})$ & $\mathrm{HCO}_{3}^{-}(\mathrm{mmo} / \mathrm{L})$ \\
\hline Control & $2.61 \pm 0.44$ & $80.4 \pm 6.31$ & $91.2 \pm 7.54$ & $10.1 \pm 0.33$ \\
\hline MT & $2.70 \pm 0.53$ & $84.0 \pm 7.54$ & $93.0 \pm 8.35$ & $11.3 \pm 0.82$ \\
\hline ALA & $2.68 \pm 0.27$ & $82.2 \pm 7.27$ & $92.8 \pm 6.72$ & $10.5 \pm 0.44$ \\
\hline$M T+A L A$ & $2.74 \pm 0.21$ & $86.9 \pm 6.45$ & $95.4 \pm 7.63$ & $12.7 \pm 1.43$ \\
\hline MTX/CPT & $0.65 \pm 0.05^{a}$ & $37.8 \pm 3.83^{a}$ & $40.1 \pm 5.63^{a}$ & $4.36 \pm 0.23^{a}$ \\
\hline MT+MTX/CPT & $1.45 \pm 0.07^{b}$ & $58.3 \pm 4.64^{b}$ & $63.3 \pm 5.47^{b}$ & $6.92 \pm 0.17^{b}$ \\
\hline $\mathrm{ALA}+\mathrm{MTX} / \mathrm{CPT}$ & $1.00 \pm 0.04^{c}$ & $53.4 \pm 4.55^{b}$ & $51.1 \pm 4.63^{c}$ & $5.45 \pm 0.32^{c}$ \\
\hline $\mathrm{MT}+\mathrm{ALA}+\mathrm{MTX} / \mathrm{CPT}$ & $2.46 \pm 0.63^{d}$ & $76.6 \pm 6.03^{d}$ & $87.0 \pm 6.43^{d}$ & $9.83 \pm 0.49^{d}$ \\
\hline
\end{tabular}

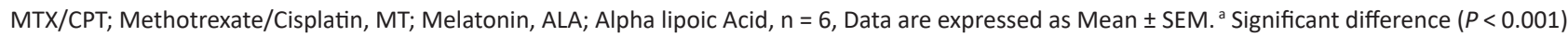
when compared to control, b Significant difference $(P<0.01)$ when compared to MTX/CPT, ${ }^{c}$ Significant difference $(P<0.05)$ when compared to MTX/ CPT, ${ }^{\text {d }}$ Significant difference $(P<0.001)$ when compared to MTX/CPT.

Table 3. Effects of melatonin and alpha lipoic acid on kidney oxidative stress markers of methotrexate/cisplatin-treated albino rats

\begin{tabular}{|c|c|c|c|c|c|}
\hline Treatments & $\begin{array}{c}\text { MDA } \\
\text { (mmol/mg protein) }\end{array}$ & $\begin{array}{c}\text { GSH } \\
(\mu \mathrm{g} / \mathrm{mg} \text { protein) }\end{array}$ & $\begin{array}{c}\text { CAT } \\
\text { (U/mg protein) }\end{array}$ & $\begin{array}{c}\text { SOD } \\
\text { (U/mg protein) }\end{array}$ & $\begin{array}{c}\mathrm{GPX}(\mathrm{U} / \mathrm{mg} \\
\text { protein) }\end{array}$ \\
\hline Control & $0.19 \pm 0.06$ & $12.1 \pm 1.44$ & $33.5 \pm 2.32$ & $27.3 \pm 2.54$ & $20.0 \pm 2.54$ \\
\hline MT & $0.17 \pm 0.04$ & $13.7 \pm 1.36$ & $36.8 \pm 2.37$ & $29.9 \pm 2.21$ & $21.1 \pm 2.43$ \\
\hline ALA & $0.18 \pm 0.03$ & $12.6 \pm 1.51$ & $34.6 \pm 2.75$ & $28.2 \pm 2.40$ & $20.7 \pm 2.76$ \\
\hline $\mathrm{MT}+\mathrm{ALA}$ & $0.16 \pm 0.06$ & $14.9 \pm 1.37$ & $37.0 \pm 2.00$ & $30.7 \pm 2.94$ & $22.3 \pm 2.19$ \\
\hline MTX/CPT & $2.60 \pm 0.14^{a}$ & $4.30 \pm 0.29^{a}$ & $8.00 \pm 0.67^{a}$ & $6.42 \pm 0.62^{a}$ & $6.36 \pm 0.03^{a}$ \\
\hline $\mathrm{MT}+\mathrm{MTX} / \mathrm{CPT}$ & $1.30 \pm 0.07^{b}$ & $6.57 \pm 0.41^{b}$ & $16.1 \pm 2.21^{b}$ & $12.0 \pm 1.47^{b}$ & $10.9 \pm 0.73^{b}$ \\
\hline $\mathrm{ALA}+\mathrm{MTX} / \mathrm{CPT}$ & $1.91 \pm 0.03^{c}$ & $6.43 \pm 0.37^{b}$ & $12.5 \pm 1.60^{c}$ & $8.53 \pm 1.32^{c}$ & $8.78 \pm 0.52^{c}$ \\
\hline $\mathrm{MT}+\mathrm{ALA}+\mathrm{MTX} / \mathrm{CPT}$ & $0.22 \pm 0.04^{d}$ & $11.8 \pm 1.50^{\mathrm{b}}$ & $30.1 \pm 3.23^{d}$ & $25.9 \pm 2.44^{d}$ & $18.9 \pm 1.22^{\mathrm{d}}$ \\
\hline
\end{tabular}

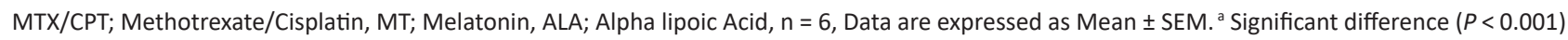
when compared to control, ${ }^{b}$ Significant difference $(P<0.01)$ when compared to MTX/CPT, ${ }^{c}$ Significant difference $(P<0.05)$ when compared to MTX/ CPT, ${ }^{\text {d }}$ Significant difference $(P<0.001)$ when compared to MTX/CPT.

MTX/CPT-treated rats as shown by elevated serum levels of creatinine, urea, and uric acid, with decreased serum total protein and albumin. This observation is a clear sign of kidney toxicity (37). However, the functional capacity of the kidney was restored in rats pretreated with individual doses of MT and ALA as shown by normal levels of the aforementioned renal function markers. The functional capacity of the kidney was most restored in rats pretreated with MT+ALA.

The kidneys play pivotal roles in the regulation of serum electrolytes and acid-base balance. The progressive loss of kidney function produces derangement in serum electrolytes and acid-base balance and contributes to serious health complications (38). In this study, serum electrolytes were normal in rats treated with MT and ALA, but were decreased in MTX/CPT-treated rats. The decreases in serum electrolytes observed in MTX/CPTtreated rats are evidence of impaired renal hemodynamics (39). On the other hand, serum electrolytes were stabilized in rats pretreated with individual doses MT and ALA with most stabilized levels observed in rats pretreated with MT+ALA.

The production of free radicals is essential for normal cellular functions, but excess production from exogenous or endogenous sources can lead to OS which has been implicated in the pathogenesis of many diseases. The 

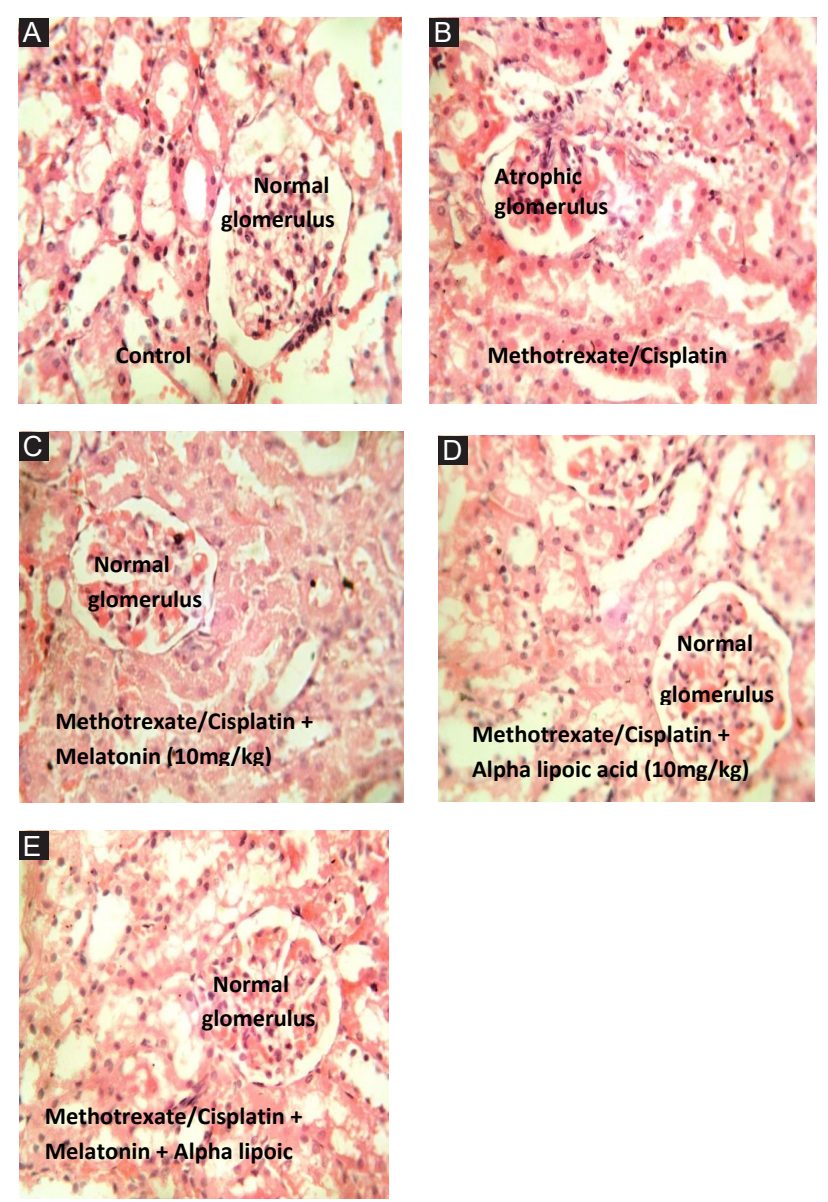

Figure 6. (A) Control kidney showing normal glomerulus. (B) Kidney of rat treated with methotrexate/cisplatin $20 / 5 \mathrm{mg} / \mathrm{kg}$ showing atrophic glomerulus. (C). Kidney of rat treated with methotrexate/cisplatin $+10 \mathrm{mg} /$ $\mathrm{kg}$ of melatonin showing normal glomerulus. (D) Kidney of treated with methotrexate/cisplatin $+10 \mathrm{mg} / \mathrm{kg}$ of alpha lipoic acid showing normal glomerulus. (E) Kidney of rat treated with methotrexate/cisplatin $+10 \mathrm{mg} /$ $\mathrm{kg}$ of melatonin $+10 \mathrm{mg} / \mathrm{kg}$ of alpha lipoic acid showing normal glomerulus $(H \& E) \times 400$

physiological role of antioxidants is to prevent damage to cellular components arising as a consequence of chemical reactions involving free radicals (40). GPX, SOD, and CAT are first line antioxidant defense that preserve the structure and function of cells with the advent of excess actions of free radicals. However, they can be consumed, depleted and their actions reduced with sustained excess activities of free radicals (40). The current study observed decreases in kidney GPX, SOD, CAT and GSH levels in MTX/ CPT-treated rats. This observation gives credence to the involvement of OS in MTX/CPT-induced kidney toxicity. However, kidney antioxidants were stabilized in MT and ALA-pretreated rats. The toxic secondary messengers generated during LPO can impair the physical properties of lipid bilayers such as alterations in ion gradients, membrane permeability, lipid-lipid interactions, and membrane fluidity (41). Studies have shown that LPO is involved in the pathogenesis of many pathologies and cell death. MDA is one of the most important LPO metabolites and is primarily used as an excellent index for LPO (41). In this study, MDA levels were elevated in the kidneys of rats treated with MTX/CPT. This observation is an evidence of the involvement of LPO in nephrotoxicity caused by MTX/CPT. However, the kidney levels of MDA were decreased in rats pretreated with individual doses of MT and ALA with most decrease observed in rats pretreated with MT+ALA. MTX/CPT-induced kidney toxicity can be characterised by necrotic changes in kidney morphology (42). The present study observed atrophic glomeruli in the kidneys of MTX/CPT-treated rats. However, this was abrogated in MT and ALA pretreated rats as evidenced by normal glomeruli and renal tubules. The observed nephrotoxic effect of MTX/CPT may be due to direct toxic effect on the kidney. In addition, MTX/CPT might have cause OS through ROS production which might have attacked cellular proteins, lipids and nucleic acids leading to morphological and functional changes in the kidney (43). Furthermore, MTX/CPT might have induced inflammation because individually, these drugs can stimulate the production of pro-inflammatory cytokines such as TNF- $\alpha$, IL-1 $\beta$ and IL- 6 which can cause cascade of events leading to kidney damage (44). In the current study, MT and ALA might have safeguarded the kidneys of MTX/CPT-treated rats by preventing or terminating OS through scavenging ROS, up-regulating antioxidant gene expression thereby stimulating GPX, SOD, CAT and GSH activities (45). The aforementioned actions of MT and ALA might have protected kidney DNA, lipids and proteins from damage caused by ORS (46). Furthermore, MT and ALA might have inhibited the stimulatory effect of MTX/CPT on inflammatory process because, studies have shown that MT and ALA can inhibit the production of pro-inflammatory cytokines such as TNF- $\alpha$, IL- $1 \beta$ and IL-6 which are implicated in drug-induced nephrotoxicity (47). The best nephroprotective effect obtained in rats pretreated with MT +ALA may be due to their stimulatory effects on each other's antioxidant and anti-inflammatory activities.

\section{Conclusion}

MT and ALA might have prevented kidney injury induced by MTX/CPT through the inhibition of OS and inflammation.

\section{Acknowledgments}

The authors appreciate Dr Yibala Obuma of the Department of Medical Laboratory Sciences, Faculty of Basic Medical Sciences, Niger Delta University, Nigeria for histological evaluation. Also, we are grateful to $\mathrm{Mr}$ Cosmos Obi of the Department of Pharmacology/ Toxicology, Faculty of Pharmacy, Niger Delta University, Nigeria for animal handling and sacrifice.

Authors' contribution

EA; Study design, literature search and review, animal 
handling, data collection, data analysis, manuscript preparation and revision. NE; Data collection, literature review, manuscript preparation and revision. BB; Data collection, literature review, manuscript preparation and revision.

\section{Conflicts of interest}

Authors declare that there was no conflict of interest.

\section{Funding/Support}

None.

\section{References}

1. Chou TC. Theoretical basis, experimental design, and computerized simulation of synergism and antagonism in drug combination studies. Pharmacol Rev. 2006;58 621681.

2. Bayat Mokhtari R, Homayouni TS, Baluch N, Morgatskaya E, Kumar S, Das B, et al. Combination therapy in combating cancer. Oncotarget. 2017;8:38022-43. doi: 10.18632/ oncotarget.16723.

3. Yumura Y, Kasuga J, Kawahara T, Miyoshi Y, Hattori Y, Teranishi J, et al. Cisplatin, Methotrexate and Bleomycin for Advanced Recurrent or Metastatic Penile Squamous Cell Carcinoma. Andrology (Los Angel). 2017;6:194. doi: 10.4172/2167-0250.1000194.

4. Loehrer PJ Sr, Einhorn LH, Elson PJ, Crawford ED, Kuebler $\mathrm{P}$, Tannock I, et al. A randomized comparison of cisplatin alone or in combination with methotrexate, vinblastine, and doxorubicin in patients with metastatic urothelial carcinoma: a cooperative group study. J Clin Oncol. 1992;10:1066-73 . doi: 10.1200/JCO.1992.10.7.1066.

5. Harker WG, Meyers FJ, Freiha FS, Palmer JM, Shortliffe LD, Hannigan JF, et al. Cisplatin, methotrexate, and vinblastine (CMV): an effective chemotherapy regimen for metastatic transitional cell carcinoma of the urinary tract. A Northern California Oncology Group study. J Clin Oncol. 1985;3: 1463-70. doi:10.1200/JCO.1985.3.11.1463.

6. Kumar SM, Biswas S, Sarkar S, Mandal SS, Biswas J. Analytical study on the efficacy of neoadjuvant chemotherapy using a combination of methotrexate, bleomycin, and cisplatin in the management of advanced squamous cell carcinoma of the buccal mucosa. Indian J Med Paediatr Oncol .2017;38:345-8. doi: 10.4103/ijmpo. ijmpo_123_17.

7. El-Sayed EM, Mansour AM, Ghobara MY. Abrogation of cisplatin-induced nephrotoxicity in rats by Berne date extract through ameliorating oxidative stress, inflammation and apoptosis. Int J Pharma Sci Res. 2015;6:1226-33.

8. Rashid S, Ali N, Nafees S, Hasan SK, Sultana S. Mitigation of 5-Fluorouracil induced renal toxicity by chrysin via targeting oxidative stress and apoptosis in wistar rats. Food Chem Toxicol. 2014;66:185-93. doi: 10.1016/j. fct.2014.01.026.

9. Kirbas A, Cure CM, KalkanY, Cure E, Tumkaya L, Sahin $\mathrm{OZ}$, et al. Effect of infliximab on renal injury due to methotrexate in rat. Iran J Kidney Dis. 2015;9:221-9.

10. Galano A, Tan DX, Reiter RJ. Melatonin as a neutral ally against oxidative stress. J Pineal Res. 2011;51:1-16. doi:
10.1111/j.1600-079X.2011.00916.x.

11. Hardeland R. Melatonin in plants - diversity of levels and multiplicity of functions. Int J Mol Sci. 2019;20:1223.

12. Gobbo MG, Costa CF, Silva DG, de Almeida EA, Góes RM. Effect of melatonin intake on oxidative stress biomarkers in male reproductive organs of rats under experimental diabetes. Oxid Med Cell Longev. 2015;2015:614579. doi: 10.1155/2015/614579.

13. Peerapanyasut W, Kobroob A, Palee S, Chattipakorn N, Wongmekiat $\mathrm{O}$. Activation of sirtuin 3 and maintenance of mitochondrial integrity by $\mathrm{N}$-acetylcysteine protects against bisphenol A-induced kidney and liver toxicity in rats. Int J Mol Sci. 2019;20:267. doi: 10.3390/ijms20020267

14. Nabavi SM, Nabavi SF, Sureda A, Xiao J, Dehpour AZ, Shirooie S, et al. Anti-inflammatory effects of melatonin: a mechanistic review. Crit Rev Food Sci Nutr. 2019;59(sup1):S4-16.doi:10.1080/10408398.2018.14879.27.

15. Scholich H, Murphy M, Sies H. Antioxidant activity of dihydrolipoate against microsomal lipid peroxidation and its dependence on alpha-tocopherol. Biochim Biophys Acta. 1989;1001:256-61. doi:10.1016/0005-2760(89)901082.

16. Posadzki PP, Bajpai R, Kyaw BM, Roberts NJ , Brzezinski A, Christopoulos GI, et al. Melatonin and health: an umbrella review of health outcomes and biological mechanisms of action. BMC Med. 2018;16:18. doi: 10.1186/s12916-0171000-8.

17. Gorąca A, Huk-Kolega H, Piechota A, Kleniewska P, Ciejka E, Skibska B. Lipoic acid-biological activity and therapeutic potential. Pharmacol Rep. 2011;63:849-58.

18. Scholich H, Murphy M, Sies H. Antioxidant activity of dihydrolipoate against microsomal lipid peroxidation and its dependence on alpha-tocopherol. Biochim Biophys Acta. 1989;1001:256-261

19. Sudheesh NP, Ajith TA, Janardhanan KK. Hepatoprotective effects of DL-alpha-lipoic acid and alpha-tocopherol through amelioration of the mitochondrial oxidative stress in acetaminophen challenged rats. Toxicol Mech Methods. 2013;23:368-76. doi: 10.3109/15376516.2013.769289.

20. Perera J, Tan J H, Jeevathayaparan S, Chakravarthi S, Haleagrahara N. Neuroprotective effects of alpha lipoic acid on haloperidol-induced oxidative stress in the rat brain. Cell Biosci. 2011;1:12. doi: 10.1186/2045-3701-1-12.

21. El-Beshbishy HA, Bahashwan SA, Aly HA, Fakher HA. Abrogation of cisplatin-induced nephrotoxicity in mice by alpha lipoic acid through ameliorating oxidative stress and enhancing gene expression of antioxidant enzymes. Eur J Pharmacol. 2011;668:278-84. doi: 10.1016/j. ejphar.2011.06.051.

22. Tahira A, Saleem U, Mahmood S, Hashmi FK, Hussain K, Bukhari NI, et al. Evaluation of protective and curative role of alpha-lipoic acid and selenium in gentamicin-induced nephrotoxicity in rabbits. Pak J Pharm Sci. 2012;25:103--10.

23. Gomes MB, Negrato CA. Alpha-lipoic acid as a pleiotropic compound with potential therapeutic use in diabetes and other chronic diseases. Diabetol Metab Syndr. 2014;6:80. doi: 10.1186/1758-5996-6-80.

24. Adikwu E, Braimbaifa N, Obianime AW. Melatonin and alpha lipoic acid as possible therapies for lopinavir/ ritonavir-induced hepatotoxicity in albino rats. Physiol 
Pharmacol. 2016;20:287-95

25. Adikwu E, Bokolo B. Effect of Ocimum gratissimum on methotrexate -induced nephrotoxicity. Asian J Med Sci. 2018;9: 37-43

26. Naghizadeh B, Boroushaki MT, Vahdati Mashhadian N, Mansouri MT. Protective effects of crocin against cisplatininduced acute renal failure and oxidative stress in rats. Iran Biomed J. 2008;12:93-100.

27. Buege JA, Aust SD. Microsomal lipid peroxidation. Methods Enzymol. 1978;52:302-310. doi: 10.1016/S00766879(78)52032-6.

28. Sedlak J, Lindsay RH. Estimation of total, proteinbound and non-protein sulfhydryl groups in tissue with Ellman's reagent. Anal Biochem. 1968;25:192-205. doi: 10.1016/0003-2697(68)90092-4.

29. Misra HP, Fridovich I. The role of superoxide anion in the autoxidation of epinephrine and a simple assay for superoxide dismutase. J Biol Chem. 1972;247:3170-5.

30. Aebi H. Catalase in vitro. Methods Enzymol. 1984;105:1216. doi: 10.1016/s0076-6879(84)05016-3.

31. Rotruck JT, Pope AL, Ganther HE, Swanson AB, Hafeman DG, Hoekstra WG. Selenium: biochemical role as a component of glutathione peroxidase. Science .1973;179: 588-90. doi: 10.1126/science.179.4073.588.

32. Nikanjam M, Liu S, Yang J, Kurzrock R .Dosing three-drug combinations that include targeted anti-cancer agents: analysis of 37,763 patients. Oncologist. 2017;22:576-84. doi: 10.1634/theoncologist.2016-0357.

33. Elias A, Ogbuehi I, Edikpo NJ, Oputiri D, PG Oru-Bo. Tenofovir renal toxicity: evaluation of cohorts and clinical studies-part one. Pharmacol Pharm. 2014;5:97-111. doi: 10.4236/pp.2014.51015.

34. Abdel-Daim MM, Khalifa HA, Abushouk AA, Dkhil MA, Al-Quraishy SA. Diosmin attenuates methotrexateinduced hepatic, renal, and cardiac injury: a biochemical and histopathological study in mice. Oxid Med Cell Longev. 2017;2017:3281670. doi: 10.1155/2017/3281670.

35. Adikwu E, Nelson EC, Yambozibe AS. Comparative protective assessments of some antioxidants against cyclophosphamide-induced kidney toxicity in albino rats. J Nephropharmacol. 2019;8:e22. doi: 10.15171/npj.2019.22 36. Gowda S, Desai PB, Kulkarni SS, Hull VV, Math AK,
Vernekar SN. Markers of renal function tests. N Am J Med Sci. 2010;2:170-3.

37. Morsy MA, Ibrahim SA, Amin FE, Kamel MY, Rifaai RA, Hassan MK. Curcumin ameliorates methotrexateinduced nephrotoxicity in rats. Adv Pharmacol Sci. 2013;2013:387071. doi: 10.1155/2013/387071.

38. Dhondup T, Qian Q. Electrolyte and acid-base disorders in chronic kidney disease and end-stage kidney failure. Blood Purif. 2017;43:179-88. doi: 10.1159/000452725.

39. Ahmed W, Zaki A, Nabil T. Prevention of methotrexateinduced nephrotoxicity by concomitant administration of garlic aqueous extract in rat. Turk J Med Sci. 2015;45: 507516

40. Young IS, Woodside JV. Antioxidants in health and disease. J Clin Pathol .2001;54:176-86.

41. Gaschler MM, Stockwell BR. Lipid peroxidation in cell death. Biochem Biophys Res Commun. 2017;482:419-25. doi: $10.1016 /$ j.bbrc.2016.10.086.

42. Abdou RH, Abdel-Daim MM. Alpha-lipoic acid improves acute deltamethrin-induced toxicity in rats. Can J Physiol Pharmacol. 2014;92:773-9. doi: 10.1139/cjpp-2014-0280.

43. Vardi N, Parlakpinar H, Ates B, Cetin A, Otlu A. The protective effects of Prunus armeniaca L (apricot) against methotrexate-induced oxidative damage and apoptosis in rat kidney. J Physiol Biochem. 2013;69:371-81.

44. Meng H, Fu G, Shen J, Shen K, Xu Z, Wang Y, et al. Ameliorative effect of daidzein on cisplatin-induced nephrotoxicity in mice via modulation of inflammation, oxidative stress, and cell death. Oxid Med Cell Longev. 2017;2017:3140680. doi: 10.1155/2017/3140680.

45. Adamczyk-Sowa M, Pierzchala K, Sowa P, Mucha S, Sadowska-Bartosz I, Adamczyk J, et al. Melatonin acts as antioxidant and improves sleep in MS patients. Neurochem Res. 2014;39:1585-93. doi: 10.1007/s11064-014-1347-6.

46. Reiter RJ, Tan DX, Mayo JC, Sainz RM, Leon J, Czarnocki Z. Melatonin as an antioxidant. Acts Biochem Pol. 2003;50:1129-46.

47. Onk D, Onk OA, Turkmen K, Erol SH, Ayazoglu TA, Keles ON, et al. Melatonin attenuates contrastinduced nephropathy in diabetic rats: the role of interleukin-33 and oxidative stress. Med Inflamm. 2016;10. doi:10.1155/2016/9050828

Copyright $\odot 2020$ The Author(s); Published by Published by Society of Diabetic Nephropathy Prevention. This is an open-access article distributed under the terms of the Creative Commons Attribution License (http://creativecommons.org/licenses/by/4.0), which permits unrestricted use, distribution, and reproduction in any medium, provided the original work is properly cited. 